\title{
Phytophthora Root Rot Mortality in Fraser Fir Seedlings
}

\section{John Frampton ${ }^{1}$ and D.M. Benson ${ }^{2}$ North Carolina State University, Raleigh, NC 27695}

Additional index words. Phytophthora cinnamomi Rands, Abies fraseri (Pursh) Poir., disease resistance, Christmas trees

\begin{abstract}
Seventeen-month-old seedlings from three fraser fir (Abies fraseri [Pursh] Poir.) seed sources (Mount Mitchell, Richland Balsam and Roan Mountain) were inoculated in an outdoor lath house with five genotypes of Phytophthora cinnamomi Rands. After 122 days, overall mortality was $90.5 \%$ with significant $(p \leq 0.07)$ differences among seed sources. The Mount Mitchell source had lower mortality $(83.2 \%)$ than the Roan Mountain source $(95.8 \%)$, while the Richland Balsam source $(92.5 \%)$ was intermediate. Mortality curves were developed using nonlinear regression (Richards' function). Due to a significant seed source $x$ inoculum genotype interaction $(p \leq 0.0001)$, equations were developed for each combination of seed source and inoculum genotype. Results suggest that while the overall frequency of resistance in fraser fir is low, seed sources differ in their frequency of resistance and that more than one resistance gene may be present. Survivors from this or similar inoculations could be cloned via grafting or rooted cuttings for further resistance testing and/or grafted into a Phytophthora-resistant fraser fir seed orchard.
\end{abstract}

Production of fraser fir (Abies fraseri [Pursh] Poir.) cultured for Christmas trees has developed into a significant industry in western North Carolina over the last 25 years with annual revenues exceeding $\$ 100$ million and 5.5 to $6.0 \times 10^{6}$ trees harvested yearly (McKinley, 1996). Throughout the region, significant mortality occurs in many Christmas tree plantations due to a root rot disease caused and Grand, 2000). Development of disease resistant planting stock is urgently needed since chemical methods for controlling this disease in infested plantations is largely a stop gap measure (Sidebottom et al., 1995). Despite the widespread use of genetic resistance in combating disease caused by Phytophthora spp. in agriculture and horticulture (Erwin and Ribeiro, 1996), very little is known about the genetic resistance of fraser fir to $P$. cinnamomi. The objective of this study was to understand the relationship between geographic sources of fraser fir seedlings and $P$. cinnamomi isolates in determining disease mortality.

\section{Materials and Methods}

Seventeen-month-old seedlings from three fraser fir seed sources (Mt. Mitchell, Richland Balsam and Roan Mt.) were inoculated in an outdoor lath house with five $P$. cinnamomi isolates using techniques described by Benson et al. (1997) (total $n=360$ inoculated and 36 control seedlings). The isolate numbers and (in parenthesis) their respective isolation tech-

Received for publication 6 Feb. 2003. Accepted for publication 7 July 2003. The North Carolina Biotechnology Center and the N.C. Agricultural Research Service via the Christmas Tree Genetics Program funded this research. Special thanks are extended to Kala Parker, Chris Hunt, and Anne Margaret Braham for technical support.

${ }^{1}$ Department of Forestry.

${ }^{2}$ Department of Plant Pathology. by Phytophthora cinnamomi Rands (Benson nique, host, and county of origin follow: 2373 (single spore, fraser fir, Ashe Co., N.C.), 2376 (hyphal tip, fraser fir, Watauga Co., N.C.), 2378 (hyphal tip, fraser fir, Avery Co., N.C.), 2386 (multi-genotype, azalea, Clemson Co., S.C.), and 2391 (hyphal tip, fraser fir, Jackson Co., N.C.). Surviving seedlings were reinoculated 80 days after the original inoculation. Seedling mortality was assessed biweekly beginning 24 $\mathrm{d}$ and ending $122 \mathrm{~d}$ after the original inoculation. Mortality curves were developed using a function described by Richards (1959):

Mortality $(\%)=\alpha\left(1-\mathrm{e}^{(-\beta \mathrm{t})}\right)^{\mathrm{C}}$

where, $\mathrm{e}=$ base of natural logarithm, $\mathrm{t}=$ time (d) from initial inoculation, and $\alpha, \beta$, and $\mathrm{C}=$ regression coefficients.

\section{Results and Discussion}

Final overall mortality was $90.5 \%$, with slight differences $(P \leq 0.07)$ among seed sources. The highest mortality occurred in the Roan Mt. source and the lowest in the Mt. Mitchell source, with the Richland Balsam source intermediate $(95.8 \%, 83.2 \%$, and $92.5 \%$ respectively). Apparently, these isolated fraser fir populations differ in the frequency of resistant genotypes and hence, the frequency of resistance genes. Inoculum isolate main effects were not significant, however, due to a significant seed source $\times$ inoculum isolate interaction $(P<0.0001)$, mortality equations were developed for each combination of seed source and inoculum isolate (Fig. 1). As an

Fig. 1. Mortality curves for three sources of fraser fir seedlings after inoculation with five isolates of Phytophthora cinnamomi: Mount Mitchell (A), Richland Balsam (B), and Roan Mountain (C). Refer to text for information on inoculum sources.
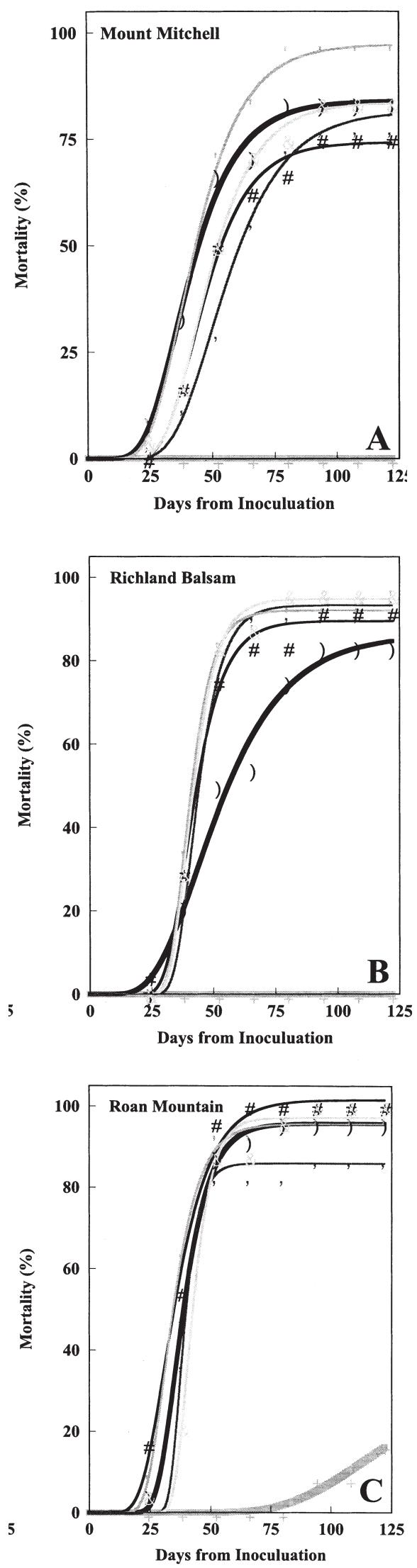

Inoculum Source

2373 -- Predicted 2373 - Actual $=2376$ - Predicted 2376 -- Actual - 2378 - Predicted 2378 -- Actual

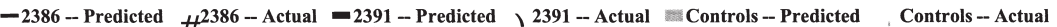


example of the interaction, isolate 2386 was least and most virulent on the Mt. Mitchell and Roan Mt. sources, respectively. This strong seed source $x$ inoculum isolate interaction suggests that more than one resistance gene may be present in these populations.

These results are important to Christmas tree growers since Roan Mt. seedlings are extensively planted due to their wide availability from the state nursery and other industry suppliers. While mortality within the Mount Mitchell source was lowest, it was too high to be of value to Christmas growers without further selection for resistance. However, this study suggests a method of developing Phytophthora-resistant fraser fir. Survivors from similar inoculations could be clonally multiplied via rooted cutting or tissue culture techniques, their resistance challenged against other P. cinnamomi isolates, and eventually evaluated under highly infested field conditions. Ultimately, clonal material with proven resistance could be released to growers or incorporated as parents in a seed orchard. Due to the significant seed source $x$ inoculum isolate interaction, precautions in matching host resistance with prevalent pathogen genotypes at deployment sites would be necessary.

\section{Literature Cited}

Benson, D.M., L.E. Hinesley, J. Frampton, and K.C. Parker. 1997. Evaluation of six Abies spp. to phytophthora root rot caused by Phytophthora cinnamomi. APS Biol. Cult. Tests 13:57.

Benson, D.M. and L.F. Grand. 2000. Incidence of phytophthora root rot of fraser fir in North Carolina and sensitivity of isolates of Phytophthora cinnamomi to metalaxyl. Plant Dis. 84: 661-664.

Erwin, D.C. and O.K. Ribeiro. 1996. Phytophthora diseases worldwide. APS Press. St. Paul, Minn.

McKinley, C.R. 1996. North Carolina's Christmas Tree Industry. N.C. Coop. Ext. Serv. Memorandum. Raleigh.

Richards, F.J. 1959. A flexible growth function for empirical use. J. Expt. Bot. 10(29):290-300.

Sidebottom, J.R. 1995. Control of phytophthora root rot in fraser fir Christmas trees. N.C. Coop. Ext. Ser. N.C. State Univ. Christmas Tree Note 022. 